УДК 539.3

\title{
Asymptotic crack tip fields in linear and nonlinear materials and their role in crack propagation
}

\author{
B.L. Karihaloo ${ }^{1}$ and Q.Z. Xiao ${ }^{2}$ \\ ${ }^{1}$ School of Engineering, Cardiff University, Cardiff, CF24 3AA, United Kingdom \\ ${ }^{2}$ LUSAS Finite Element Analysis Ltd., Kingston-upon-Thames KT1 1HN, United Kingdom
}

The famous Wieghardt, Griffith and Irwin criteria predict the onset of fracture in linear elastic materials. They have to be supplemented by appropriate criteria for predicting the path that the fracture will follow until the failure of the structure. These require the knowledge of the stress and displacement fields at the front of propagating fracture which depend on the actual loading on the structure and its boundary conditions. In this paper we shall review these fields in brittle and quasi-brittle materials. In the latter materials, a tractionfree fracture front often has a large process zone ahead of it in which the material experiences progressive softening. Such a mixed traction-free and process zone is also called a cohesive crack. Over the process zone the material is able to transfer some tractions across the crack faces depending upon how much the faces have separated or slid relative to each other. In the famous Barenblatt model the process zone was very small in comparison with the traction-free crack so that the actual traction-separation relationship in the process zone was not explicitly involved. However, in real quasi-brittle materials the size of the process zone can be commensurate or even larger than the traction-free crack. It is therefore necessary to know this relationship explicitly in order to determine the corresponding stress and displacement fields at the front of the propagating cohesive crack. The asymptotic fields at the front of a crack in brittle materials were obtained by Williams and those for quasi-brittle materials by Xiao and Karihaloo.

Keywords: quasi-brittle materials, fracture process zone, asymptotic fields, cohesion-separation laws, Coulomb friction

DOI $10.24411 / 1683-805 \mathrm{X}-2018-16005$

\section{Асимптотические поля в вершине трещины в линейных и нелинейных материалах и их роль в распространении трещин}

\author{
B.L. Karihaloo ${ }^{1}$ and Q.Z. Xiao ${ }^{2}$ \\ Кардиффский университет, Кардифф, CF24 3АA, Великобритания \\ ${ }^{2}$ Компания LUSAS Finite Element Analysis Ltd., Кингстон-апон-Темс, KT1 1HN, Великобритания
}

\begin{abstract}
Известные критерии Вигхардта, Гриффитса и Ирвина позволяют предсказывать начало разрушения в линейных упругих материалах. Однако для прогнозирования траектории распространения трещины до момента разрушения конструкции необходимо введение дополнительных критериев. Это требует знания полей напряжений и перемещений в вершине растущей трещины, которые зависят от действующей на конструкцию нагрузки и ее граничных условий. В работе рассмотрены данные поля в хрупких и квазихрупких материалах. В последних перед свободным от сил сцепления фронтом разрушения часто наблюдается большая зона процесса или предразрушения, в которой происходит постепенное разупрочнение материала. Такая смешанная зона, состоящая из области, свободной от сил сцепления, и зоны процесса, названа когезионной зоной трещины. В зоне предразрушения материал еще способен передавать некоторые силы сцепления через поверхности трещины в зависимости от степени раскрытия или сдвига ее берегов относительно друг друга. В известной модели Баренблатта зона предразрушения очень мала по сравнению с трещиной, свободной от сил сцепления, ввиду чего фактическое соотношение сил сцепления и разделения в зоне предразрушения не использовалось в явном виде. Однако в реальных квазихрупких материалах размер зоны предразрушения может быть соразмерным или даже большим, чем свободная от сил сцепления трещина. Поэтому для определения соответствующих полей напряжений и смещений в вершине растущей когезионной трещины необходимо знать данное соотношение. Ранее асимптотические поля в вершине трещины были определены для хрупких (Williams) и квазихрупких материалов (Xiao and Karihaloo).

Ключевые слова: квазихрупкие материалы, зона предразрушения, асимптотические поля, соотношение сил сцепления и разделения, кулоновское трение
\end{abstract}

\section{Introduction}

The famous Wieghardt [1], Griffith [2] and Irwin [3] criteria predict the onset of fracture in linear elastic struc- tures. They have to be supplemented by appropriate criteria for predicting the path that the fracture will follow until the failure of the structure, even in the less relevant (from 
an engineering point of view) brittle materials in which the onset of fracture is immediately followed by catastrophic fast failure. These supplementary criteria require the knowledge of the stress and displacement fields at the front of propagating fracture which depend on the actual loading on the structure and its boundary conditions. In this paper we shall review these fields in brittle and quasi-brittle materials. In the latter materials, a traction-free fracture front often has a large process zone ahead of it in which the material experiences progressive softening. Such a mixed traction-free and process zone is also called a cohesive crack. Over the process zone the material is able to transfer some traction across the crack faces depending upon how much the faces have separated or slid relative to each other. In the famous Barenblatt model $[4,5]$ the process zone was very small in comparison with the traction-free crack so that the actual traction-separation relationship in the process zone was not explicitly involved. However, in real quasi-brittle materials the size of the process zone can be commensurate with, or larger than, the traction-free crack. It is therefore necessary to know this relationship explicitly in order to determine the corresponding stress and displacement fields at the front of the propagating cohesive crack. The asymptotic fields at the front of a crack in brittle materials were obtained by Williams [6] and those for quasibrittle materials by Xiao and Karihaloo [7, 8].

This paper is organised as follows. Sections 2-4 give a brief overview of the Griffith and Irwin fracture criteria and shows that they are equivalent for brittle materials. In both these linear elastic fracture models the entire body remains elastic during the fracture process, and energy is only dissipated at a point (the crack tip). It is clear that these two features of linear elastic fracture mechanics contravene the basic tenets of the linear theory of elasticity relating to small strains and Hooke's law. The first attempt at including the cohesive forces in the crack tip region within the limits of elasticity theory was made by Barenblatt $[4,5]$ which is briefly described in this sections. Sections 5, 6 give the asymptotic fields at the tip of a traction-free crack in an elastic material and describes how the coefficients appearing in these fields can be accurately estimated for some standard fracture test specimen geometries. Section 7 deals with the Hillerborg fracture criteria for quasi-brittle materials for which the notion of crack cohesion-separation laws in the (large) fracture process zone is introduced. Sections 8-11 give the asymptotic fields at the tip of a cohesive crack. The universal asymptotic expansions at a cohesive crack tip are analogous to Williams' expansions at a traction-free crack tip. The coefficients of the expansions of course depend nonlinearly on the softening law and the boundary conditions. These universal expansions are valid for any normal cohesion-separation law (i.e. softening law) that can be expressed in a special polynomial form. It will be demonstrated that many commonly-used cohesion-separation laws, e.g. rectangular, linear, bilinear and exponential, can indeed be expressed very accurately in this special form. The universal asymptotic expansions are also given when the cohesive crack faces are subjected to Coulomb friction.

\section{Griffith theory of brittle fracture}

In a celebrated paper, Griffith [2] explained theoretically the reason that the real tensile strength of hard brittle materials is significantly lower than their theoretically predicted strength by considering the effect of small cracks and/or other crack-like defects. Cracks introduce high stress concentrations near their tips in an elastic brittle material and therefore, the tensile strength of material is exceeded earlier than when the stress is uniformly distributed in the material. For a slit-like cut in an elastic material the stress field is singular at the tips, no matter how small the applied tensile force is. Griffith [2] deduced this from the solution of Inglis [9] for an elliptical hole in a large elastic panel whose linear dimensions are much larger than its thickness and which is subjected to a uniform far-field tension. The cut induces a biaxial stress state near the tips. The vertical displacement of the upper face of the cut can also be deduced from the Inglis solution. The slit-like cut takes the form of an elongated ellipse under tensile loading. With reference to Fig. 1, the elastic plate with a slit-like cut of length $2 a$ can be considered as the superposition of an elastic
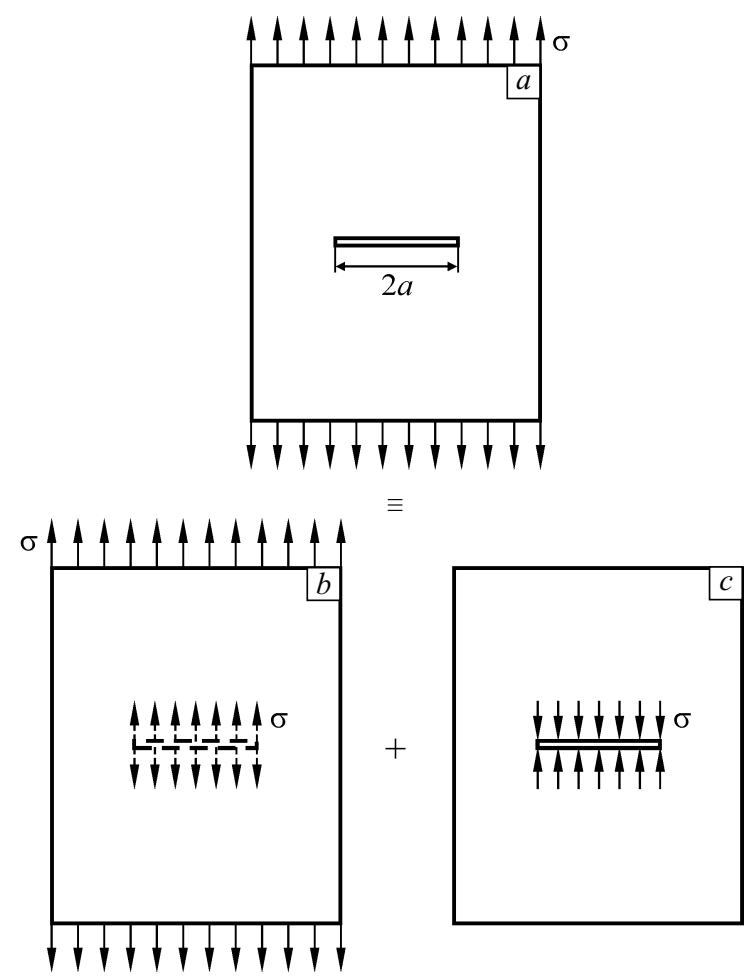

Fig. 1. The principle of superposition: the plate is under external tension $(a)$; uncracked plate under $\sigma(b)$; plate without external $\sigma$ but with equal and opposite stress applied to the crack to create a stress-free crack [10] (c) 
plate without a cut under external stress $\sigma$ and the same plate without external $\sigma$ but with equal and opposite stresses (i.e. $-\sigma$ ) applied gradually to the faces of the intended cut in order to annul the stresses there due to the external uniform stress $\sigma$. In this process, the stress $\sigma$ on each of the two faces is displaced by the vertical displacement $v(x)$ of the crack face, so that the work done is

$$
W=2\left(-\frac{\sigma}{2} \int_{-a}^{a} v(x) \mathrm{d} x\right)=-\frac{\pi a^{2} \sigma^{2}}{E^{\prime}} .
$$

The quantity $W$ therefore is the work that can be extracted from the panel under loading. As the crack grows by a small amount $\mathrm{d} a$ at each end, energy flows into the crack tips where it is consumed in overcoming the forces binding the material. Crack propagation will occur if the energy released is sufficient to provide the energy that is required for crack growth. If the crack grows stably, then $\mathrm{d} W=-\mathrm{d} \Gamma$, where $\Gamma=4 a \gamma$ is the surface energy consumed in the creation of the cracks per unit thickness, and $\gamma$ is the surface energy density. For stable crack growth, the energy balance may be rewritten as

$$
\frac{\partial}{\partial a}(W+\Gamma)=0 \text { or }-\frac{\partial W}{\partial a}=\frac{\partial \Gamma}{\partial a} \text { or } G=R,
$$

where $G=-\partial W / \partial a$ is the energy release rate, and $R=$ $=\partial \Gamma / \partial a$ is the crack resistance.

To a first approximation it can be assumed that the energy required to produce a crack is the same for each increment of crack growth. That is, $R$ is a constant. Thus, the above crack propagation criterion can be rewritten as

$$
G=G_{\text {Ic }},
$$

where $G_{\mathrm{Ic}}$ is the critical energy release rate.

Differentiation of (1) with respect to $a$ and substitution of (2) gives

$$
\sigma^{2}=\frac{2 E^{\prime} \gamma}{\pi a}
$$

For a given material (i.e. for given $E, v$ and $\gamma$ ) it follows from formula (4) that

$$
\sigma \sqrt{\pi a}=\sqrt{2 E^{\prime} \gamma}=\text { const. }
$$

For ideal brittle materials, relation (5) has been qualitatively confirmed by experiment, e.g. by the tests that Griffith himself performed on thin glass sheets. It determines the critical stress $\sigma=\sigma_{\text {cr }}$ (the strength of a brittle material $\sigma_{\text {cr }}$ depends on physical parameters such as the Young modulus, the surface energy density, and the length of crack) at which a crack of length $2 a$ will propagate. Moreover, once the crack has started to propagate, it will continue to grow in a catastrophic manner. It is clear that the Griffith energy criterion of fracture for brittle materials is of a global character. The elastic body (e.g. the whole plate above) under external loading applied normal to, and remotely from, the crack serves as a source of energy. When the energy accumulated in the body and available for release into the crack tips, is sufficient to break the bonds ahead of the tips, catastrophic brittle fracture of the body takes place.

\section{Irwin theory of brittle fracture}

It can be noticed from the Griffith theory that the entire fracture process in a brittle body takes place at the crack tips where the stress field is singular; the rest of the body remains elastic. Irwin [3] also noted that in the neighbourhood of the sharp crack tips, the stress components are the same regardless of the shape of the elastic body and the manner of loading if the stress intensity factor (SIF), $K$ (after Kies), is the same. In linear elastic fracture mechanics, the general deformation state at a crack tip may be resolved into three elementary states which are called modes I (opening mode), II (in-plane shear mode), and III (antiplane shear mode), respectively. The Griffith problem considered above (Fig. 1) is a mode I case. The superposition of these three modes is sufficient to describe the most general 3D case of local crack tip deformation and stress fields.

The presence of cracks in an elastic body leads to a significant change in its stress state, especially in the vicinity of crack tips. In order to quantify this change it is necessary to solve mathematically the problem of equilibrium of elastic bodies containing sharp cracks. Due to mathematical difficulties, only simple problems lend themselves to closed-form solutions. For a straight through the thickness crack in a two dimensional (plane) infinite body subjected to a uniform stress remote from the crack which induces one of the above three modes of stress at the crack tips, the solutions have been found with the use of, for example, the Westergaard stress function. We shall not describe it here, but shall consider a more general method later. At this stage it is sufficient to say that the stress and displacement fields in the vicinity of a sharp crack depend on the distance from the crack tip $r$. The angular variations of stresses and displacements do not depend on the geometry of the body and the manner of loading, so long as the latter creates mode I or II or III conditions. A parameter $K_{\mathrm{I}}$ called the mode I stress intensity factor enters the mode I fields which depends on the geometry of the body and the manner in which the remote loading is applied to create mode I conditions at the crack tip. For a central crack of length $2 a$ in an infinite plate subjected to a uniform tensile stress $\sigma$ at infinity (Fig. 1)

$$
K_{\mathrm{I}}=\sigma \sqrt{\pi a} \text {. }
$$

In general, $K_{\mathrm{I}}$ is finite and non-negative. A negative $K_{\mathrm{I}}$ would require interpenetration of crack faces which is physically meaningless.

Likewise, $K_{\mathrm{II}}$ is the stress intensity factor in mode II. For the configuration of Fig. 1 but with a remotely applied uniform in-plane shear $\tau$ in place of uniform tension

$$
K_{\mathrm{II}}=\tau \sqrt{\pi a} \text {. }
$$

Similarly, $K_{\mathrm{III}}$ is the stress intensity factor in mode III. For the configuration of Fig. 1 with a remote uniform antiplane shear loading $\tau$ in place of uniform tension

$$
K_{\mathrm{III}}=\tau \sqrt{\pi a} \text {. }
$$


In all three modes of loading the stresses near a crack tip have a square-root singularity $r^{-1 / 2}$, whereas the displacements are proportional to $r^{1 / 2}$ and thus vanish as $r \rightarrow 0$. The strains would also exhibit a square-root singularity. If the stress intensity factors for two crack configurations are equal, the two cracks will respond in the same manner. The Irwin criterion for the fracture of brittle materials states that a sharp crack in the brittle material will propagate when the stress intensity factor $K_{\mathrm{I}}$ reaches a critical value, denoted $K_{\text {Ic }}$, i.e.

$$
K_{\text {I }}=K_{\text {Ic }} \text {. }
$$

This critical value is a material constant and is called the fracture toughness of the material. The distinction between $K_{\text {Ic }}$ and $K_{\mathrm{I}}$ is similar to the distinction between strength and stress. In other words, $K_{\text {Ic }}$ is related to the stress intensity factor $K_{\mathrm{I}}$ for the opening mode crack in the same way that a material's tensile strength is related to the stress in a tensile specimen. For the geometry and mode I loading of Fig. 1, Irwin's fracture criterion gives

$$
\sigma_{\mathrm{c}} \sqrt{\pi a}=K_{\mathrm{Ic}} \text {. }
$$

The geometry of the body and the loading for which (10) is valid are identical to those considered by Griffith for arriving at his energy criterion (3). We have thus arrived at a fundamental result in the theory of fracture of brittle materials, namely that the local stress criterion at the crack tip (10) where the fracture process is taking place is exactly identical to the global energy criterion (3). It should be remembered however that the stress intensity factor $K_{\mathrm{I}}$ is determined by the geometry and loading of the whole body.

The constant in the right hand side of (5) can be identified with $K_{\mathrm{Ic}}$, i.e.

$$
\sqrt{2 E^{\prime} \gamma}=K_{\mathrm{Ic}} \text { or } K_{\mathrm{Ic}}^{2}=E^{\prime} G_{\mathrm{Ic}}
$$

where $G_{\text {Ic }}(=2 \gamma)$ is the critical Griffith surface energy density or the critical energy release rate. The notion of $G$ (after Griffith) in place of $2 \gamma$ was introduced by Irwin. $G_{\text {Ic }}$ is called the toughness of the material, as opposed to $K_{\text {Ic }}$ which is its fracture toughness. It should be emphasized that the simple relation (11) between the fracture toughness $K_{\text {Ic }}$ and toughness $G_{\text {Ic }}$ is strictly valid only for ideal brittle materials. The parameter $K_{\text {Ic }}^{2} / E^{\prime}$ is sometimes regarded as the critical "force" necessary for driving the crack.

The Griffith global energy balance and the Irwin local stress criterion are in essence identical, but the Irwin SIF approach is much more convenient for practical use, because it is much easier to determine directly the fracture toughness $K_{\text {Ic }}$ from a test specimen than it is to determine the toughness $G_{\text {Ic }}$.

We did not introduce the notions of fracture toughness or toughness in modes II and III for several reasons. First, the most severe loading state for fracture is obviously the opening mode I. Secondly, it would seem impossible to propagate cracks in real materials under pure mode II or mode III conditions because of frictional forces. Thirdly, even under mixed mode conditions, it appears that locally the fracture takes place in pure mode I, although the direction of propagation depends on the mixity conditions. Thus, in pure mode I a straight crack will propagate in its own plane, whereas under mixed mode loading the crack must deviate from its plane. We shall discuss this further in a later section. The equivalence between Griffith and Irwin criteria for the onset of fracture in brittle materials can also be established from pure energy considerations at the crack tip (see, e.g. [11]).

\section{Barenblatt cohesive crack model}

Let us recapitulate the main features of linear elastic fracture mechanics outlined above. The description of brittle fracture involves only one additional material parameter, besides the usual two elastic constants $E$ and $v$. This parameter may be related to the energy of the body $\left(G_{\text {Ic }}\right)$ or to the stress field near the tip of a sharp crack present in the body $\left(K_{\text {Ic }}\right)$. The stresses and strains in the vicinity of a sharp crack tip are very large (at the tip itself they tend to infinity). During the fracture process the entire body remains elastic, and energy is only dissipated at a point (the crack tip).

The last two features of linear elastic fracture mechanics contravene the basic tenets of the linear theory of elasticity relating to small strains and Hooke's law. Griffith [2] had already noted the inconsistency between the linear elastic fracture model and the real physical situation prevailing at the crack tip. He therefore proposed that the faces of the crack should be allowed to close smoothly forming a cusp under the influence of large cohesive forces approaching the tensile strength of the brittle material.

The first attempt at including the cohesive forces in the crack tip region within the limits of elasticity theory was made by Barenblatt $[4,5]$. He assumed that large cohesive forces $q(x)$ acted in a small zone of length $c$ (the so-called cohesive zone) near the crack tip ( $c \ll a$, Fig. 2) such that the crack faces closed smoothly. The distribution of these cohesive forces is generally unknown. What is more, it is difficult to ascertain, in view of the presence of various other defects, and especially of pores and inclusions. Ba-

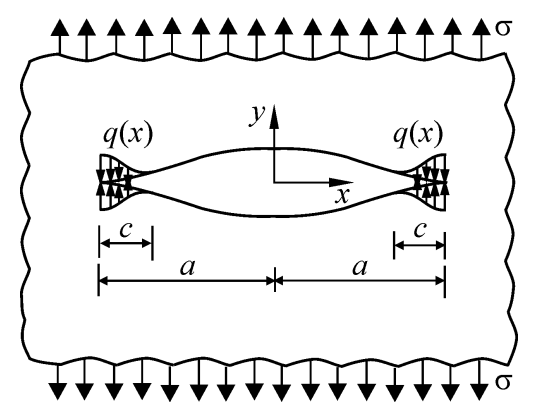

Fig. 2. Barenblatt cohesive crack model in mode I. Note $c \ll a$ 
renblatt postulated that at the critical state (i.e. at the onset of fracture) the configuration of the cohesive zone is independent of the applied loads, and for a given material and under given environmental test conditions, is always the same. Under the above assumptions and assuming that the crack faces close smoothly at the tip, he found for the mode I Griffith crack that the integral of the cohesive forces over the zone is

$$
Q=\sqrt{\pi / 2} K_{\mathrm{I}} \text {. }
$$

He termed $Q$ the modulus of cohesion and showed that it is proportional to the stress intensity factor for a crack without the cohesive zone. The length of the latter $c$ does not appear in the final result. Therefore, within the bounds of the theory of elasticity and under the postulates of smallness and invariance of the cohesive zone, Barenblatt's cohesive crack model is equivalent to the noncohesive model of Irwin and, by inference, to that of Griffith. In practice though, Irwin's linear elastic fracture model is preferred for brittle materials because there is no need to introduce cohesive forces which, as we said before, are difficult to ascertain.

Irwin [3] had also recognised that the fracture process could not be concentrated at a point but should take place over a finite, though small zone-the so-called fracture process zone (FPZ). He provided a crude estimate of its size-designated $r_{\mathrm{p}}$ - by limiting the transverse normal stress in the fracture criterion (10) to the tensile strength $f_{\mathrm{t}}^{\prime}$ of the brittle material

$$
r_{\mathrm{p}}=\frac{1}{\pi} \frac{K_{\mathrm{Ic}}^{2}}{f_{\mathrm{t}}^{\prime 2}}=\frac{1}{\pi} \frac{E^{\prime} G_{\mathrm{Ic}}}{f_{\mathrm{t}}^{\prime 2}} .
$$

To obtain the last relation we have used (11). It is clear that linear elastic fracture mechanics is only applicable, if the size of the process zone $r_{\mathrm{p}}$ is much smaller than any of the characteristic dimensions of the elastic body, including the crack. This condition is met by all linear elastic materials, and also by some elasto-plastic materials such as high strength metals $\left(f_{\mathrm{t}}^{\prime}>500 \mathrm{MPa}\right)$ which exhibit only a limited plastic deformation. Finally, it should be mentioned that Dugdale [12] and Bilby et al. [13] presented models for planar zones of plasticity at the tips of a crack in which the "cohesive" stress was constant and equal to the yield strength of the material. In their models, it was not necessary to limit the size of the cohesive (i.e. the plastic) zone at the crack tip.

\section{Linear elastic crack-tip fields}

In this section, we will first give the complete expansions of the crack tip stresses and displacements (Williams expansions) for modes I, II and III. We will then give the solution of the stress intensity factor, the $T$-stress, and coefficients of higher order terms in the Williams expansions for the three-point bend single-edge notched beam and compact tension specimens which are commonly used for de- termining $K_{\mathrm{Ic}}$. We mention though in passing that Irwin used the Westergaard complex function method to obtain the leading term of the stress and displacement fields in modes I, II and III for cracks in infinite two dimensional plates. This method is restricted to the particular situation of stresses along the line of the crack and cannot treat nonuniform loadings on the specimen boundary. On the other hand, the polynomial stress function method of Williams which we shall now briefly review allows the addition of loadings on the boundaries of the crack or specimen.

\subsection{Modes I and II}

For a crack with traction-free faces lying on the negative $x$-axis, and the polar coordinates centred at the crack tip designated $r$ and $\theta$ ( $\theta$ is measured counter-clockwise from the positive $x$-axis), Williams [6] introduced the eigenfunction expansion method by assuming the Airy stress function in the form to satisfy the biharmonic equation

$$
\begin{aligned}
& \Phi(r, \theta, \lambda)=r^{\lambda+1}\left[c_{1} \sin ((\lambda+1)(\theta+\pi))+\right. \\
& +c_{2} \cos ((\lambda+1)(\theta+\pi))+c_{3} \sin ((\lambda-1)(\theta+\pi))+ \\
& \left.+c_{4} \cos ((\lambda-1)(\theta+\pi))\right] .
\end{aligned}
$$

Satisfying the traction free conditions along $\theta= \pm \pi$ gives

$$
\lambda=n / 2 \text { ( } n \text { is a positive integer) }
$$

( $\lambda$ must be greater than zero to allow for the continuity of displacements) from the characteristic (or eigen) equation

$$
\sin (2 \pi \lambda)=0 \text {, }
$$

and the even $\Phi_{\mathrm{e}}(r, \theta)$ and odd $\Phi_{\mathrm{o}}(r, \theta)$ parts of $\Phi$ with respect to $\theta$

$$
\begin{aligned}
& \Phi_{\mathrm{e}}(r, \theta)=\sum_{n=1}^{\infty}\left\{( - 1 ) ^ { n - 1 } a _ { 2 n - 1 } r ^ { n + 1 / 2 } \left[-\cos \left(\left(n-\frac{3}{2}\right) \theta\right)+\right.\right. \\
& \left.+\frac{2 n-3}{2 n+1} \cos \left(\left(n+\frac{1}{2}\right) \theta\right)\right]+(-1)^{n} a_{2 n} r^{n+1} \times \\
& \left.\times\left[-\cos \left(\left(n-\frac{3}{2}\right) \theta\right)+\cos \left(\left(n+\frac{1}{2}\right) \theta\right)\right]\right\} \\
& \Phi_{\mathrm{o}}(r, \theta)=\sum_{n=1}^{\infty}\left\{(-1)^{n-1} b_{2 n-1} r^{n+1 / 2} \times\right. \\
& \times\left[\sin \left(\left(n-\frac{3}{2}\right) \theta\right)-\sin \left(\left(n+\frac{1}{2}\right) \theta\right)\right]+ \\
& +(-1)^{n} b_{2 n} r^{n+1}\left[-\sin \left(\left(n-\frac{3}{2}\right) \theta\right)+\right. \\
& \left.\left.+\frac{2 n-3}{2 n+1} \sin \left(\left(n+\frac{1}{2}\right) \theta\right)\right]\right\} .
\end{aligned}
$$

The even part $\Phi_{\mathrm{e}}(r, \theta)$ corresponds to the symmetric mode I problem; while the odd part $\Phi_{\mathrm{o}}(r, \theta)$ corresponds to the skew-symmetric mode II case.

Williams' approach was further extended by Sih and Liebowitz [14] using the complex function formalism of Muskhelishvili [15]. For plane crack problems, Muskhelishvili [15] showed that with the use of two analytic functions $\phi(z)$ and $\chi(z)$ of the complex variable $z$, the stress function, stresses and displacements can be respectively 
written as

$$
\begin{aligned}
& \Phi=\Re F \text { and } F(z)=\bar{z} \phi(z)+\chi(z), \\
& \sigma_{x}+\sigma_{y}=4 \Re \phi^{\prime}(z)=2\left[\phi^{\prime}(z)+\overline{\phi^{\prime}(z)}\right], \\
& \sigma_{y}-\sigma_{x}+2 i \tau_{x y}=2\left[\bar{z} \phi^{\prime \prime}(z)+\chi^{\prime \prime}(z)\right], \\
& 2 \mu(u+i v)=\kappa \phi(z)-z \overline{\phi^{\prime}(z)}-\overline{\chi^{\prime}(z)},
\end{aligned}
$$

where $\phi^{\prime}(z)=\mathrm{d} \phi(z) / \mathrm{d} z, \chi^{\prime}(z)=\mathrm{d} \chi(z) / \mathrm{d} z$.

For a general plane mixed mode I/II problem, $\phi(z)$ and $\chi(z)$ can be assumed as the following complex eigenvalue Goursat functions [14]

$$
\phi(z)=\sum_{n=0}^{\infty}\left(a_{n}^{1}+i a_{n}^{2}\right) z^{\lambda_{n}}, \chi(z)=\sum_{n=0}^{\infty}\left(b_{n}^{1}+i b_{n}^{2}\right) z^{\lambda_{n}+1}
$$

where the eigenvalues $\lambda_{n}$ and coefficients $a_{n}^{1}, a_{n}^{2}, b_{n}^{1}$ and $b_{n}^{2}$ are real.

Since the crack surfaces are traction free it follows that

$$
\sigma_{y}=\tau_{x y}=0 \text { for } \theta= \pm \pi \text {. }
$$

After meeting the above conditions, we have from the characteristic equation that

$$
\lambda_{n}=\frac{n}{2}, n=0,1,2, \ldots
$$

and

$$
-b_{n}^{1}=\frac{n / 2+(-1)^{n}}{n / 2+1} a_{n}^{1},-b_{n}^{2}=\frac{n / 2-(-1)^{n}}{n / 2+1} a_{n}^{2} .
$$

The complete series expansions of the displacement and stress fields near the tip of the crack can then be written as [16]

$$
\begin{aligned}
& u=\sum_{n=0}^{\infty} \frac{r^{n / 2}}{2 \mu}\left\{a _ { n } ^ { 1 } \left[\left(\kappa+\frac{n}{2}+(-1)^{n}\right) \cos \left(\frac{n}{2} \theta\right)-\right.\right. \\
& \left.-\frac{n}{2} \cos \left(\left(\frac{n}{2}-2\right) \theta\right)\right]-a_{n}^{2}\left[\left(\kappa+\frac{n}{2}-(-1)^{n}\right) \times\right. \\
& \left.\left.\times \sin \frac{n}{2} \theta-\frac{n}{2} \sin \left(\left(\frac{n}{2}-2\right) \theta\right)\right]\right\} \text {, } \\
& v=\sum_{n=0}^{\infty} \frac{r^{n / 2}}{2 \mu}\left\{a _ { n } ^ { 1 } \left[\left(\kappa-\frac{n}{2}-(-1)^{n}\right) \sin \left(\frac{n}{2} \theta\right)+\right.\right. \\
& \left.+\frac{n}{2} \sin \left(\left(\frac{n}{2}-2\right) \theta\right)\right]+a_{n}^{2}\left[\left(\kappa-\frac{n}{2}+(-1)^{n}\right) \times\right. \\
& \left.\left.\times \cos \left(\frac{n}{2} \theta\right)+\frac{n}{2} \cos \left(\left(\frac{n}{2}-2\right) \theta\right)\right]\right\}, \\
& \sigma_{x}=\sum_{n=1}^{\infty} \frac{n}{2} r^{n / 2-1}\left\{a _ { n } ^ { 1 } \left[\left(2+\frac{n}{2}+(-1)^{n}\right) \cos \left(\left(\frac{n}{2}-1\right) \theta\right)-\right.\right. \\
& \left.-\left(\frac{n}{2}-1\right) \cos \left(\left(\frac{n}{2}-3\right) \theta\right)\right]-a_{n}^{2}\left[\left(2+\frac{n}{2}-(-1)^{n}\right) \times\right. \\
& \left.\left.\times \sin \left(\left(\frac{n}{2}-1\right) \theta\right)-\left(\frac{n}{2}-1\right) \sin \left(\left(\frac{n}{2}-3\right) \theta\right)\right]\right\}, \\
& \sigma_{y}=\sum_{n=1}^{\infty} \frac{n}{2} r^{n / 2-1}\left\{a _ { n } ^ { 1 } \left[\left(2-\frac{n}{2}-(-1)^{n}\right) \cos \left(\left(\frac{n}{2}-1\right) \theta\right)+\right.\right. \\
& \left.+\left(\frac{n}{2}-1\right) \cos \left(\left(\frac{n}{2}-3\right) \theta\right)\right]-a_{n}^{2}\left[\left(2-\frac{n}{2}+(-1)^{n}\right) \times\right. \\
& \left.\left.\times \sin \left(\left(\frac{n}{2}-1\right) \theta\right)+\left(\frac{n}{2}-1\right) \sin \left(\left(\frac{n}{2}-3\right) \theta\right)\right]\right\},
\end{aligned}
$$

$$
\begin{aligned}
\tau_{x y} & =\sum_{n=1}^{\infty} \frac{n}{2} r^{n / 2-1}\left\{a _ { n } ^ { 1 } \left[\left(\frac{n}{2}-1\right) \sin \left(\left(\frac{n}{2}-3\right) \theta\right)-\right.\right. \\
& \left.-\left(\frac{n}{2}+(-1)^{n}\right) \sin \left(\left(\frac{n}{2}-1\right) \theta\right)\right]+a_{n}^{2}\left[\left(\frac{n}{2}-1\right) \times\right. \\
& \left.\left.\times \cos \left(\left(\frac{n}{2}-3\right) \theta\right)-\left(\frac{n}{2}-(-1)^{n}\right) \cos \left(\left(\frac{n}{2}-1\right) \theta\right)\right]\right\} .
\end{aligned}
$$

The coefficients of the leading terms in (27)-(31) (corresponding to $n=1) a_{1}^{1}$ and $a_{1}^{2}$ are related to the mode I and mode II stress intensity factors as

$$
a_{1}^{1}=K_{\mathrm{I}} / \sqrt{2 \pi}, a_{1}^{2}=-K_{\mathrm{II}} / \sqrt{2 \pi} .
$$

The second term in (27)-(31) corresponds to a uniform normal stress $\sigma_{x}=T=4 a_{2}^{1}$ acting near the crack tip in the direction parallel to the crack plane. This uniform stress field is often referred to as the elastic $T$-stress.

\subsection{Mode III}

The anti-plane shear mode III problem can be solved with

$$
\bar{Z}=\sum_{n=0}^{\infty}\left(c_{n}+i d_{n}\right) z^{\lambda_{n}}
$$

The complete series expansions of the displacement and stress fields near the tip of the mode III crack can be written as

$$
\begin{aligned}
\mu w & =\sum_{n=1,3, \ldots} c_{n} r^{n / 2} \sin \left(\frac{n}{2} \theta\right)+\sum_{n=2,4, \ldots} d_{n} r^{n / 2} \cos \left(\frac{n}{2} \theta\right), \\
\tau_{y z}= & \sum_{n=1,3, \ldots} \frac{n}{2} c_{n} r^{n / 2-1} \cos \left[\left(\frac{n}{2}-1\right) \theta\right]- \\
& -\sum_{n=2,4, \ldots} \frac{n}{2} d_{n} r^{n / 2-1} \sin \left[\left(\frac{n}{2}-1\right) \theta\right] \\
\tau_{x z}= & \sum_{n=1,3, \ldots} \frac{n}{2} c_{n} r^{n / 2-1} \sin \left[\left(\frac{n}{2}-1\right) \theta\right]+ \\
& +\sum_{n=2,4, \ldots} \frac{n}{2} d_{n} r^{n / 2-1} \cos \left[\left(\frac{n}{2}-1\right) \theta\right] .
\end{aligned}
$$

The coefficient of leading terms in (34)-(36) (corresponding to $n=1) c_{1}$ is related to the mode III stress intensity factor $K_{\mathrm{III}}$ as

$$
c_{1}=K_{\mathrm{III}} \sqrt{2 / \pi} \text {. }
$$

The second term in (34)-(36) corresponds to a uniform shear stress $\tau_{x z}=d_{2}$ acting near the crack tip.

The stress intensity factor which controls the first (i.e. the singular) term of the crack tip asymptotic field has been used for years as the single controlling parameter for the initiation of crack growth in brittle materials and materials with limited ductility. The angular variation of the leading terms of the asymptotic stresses dictates the path that the propagating crack will take. The solutions of the stress intensity factor for many practical geometries and loading conditions have been compiled in handbooks, for example, $[17,18]$. However, recent studies show higher order terms of the asymptotic field are of great relevance to predicting the constraint of elasto-plastic crack tip fields $[19,20]$ and 

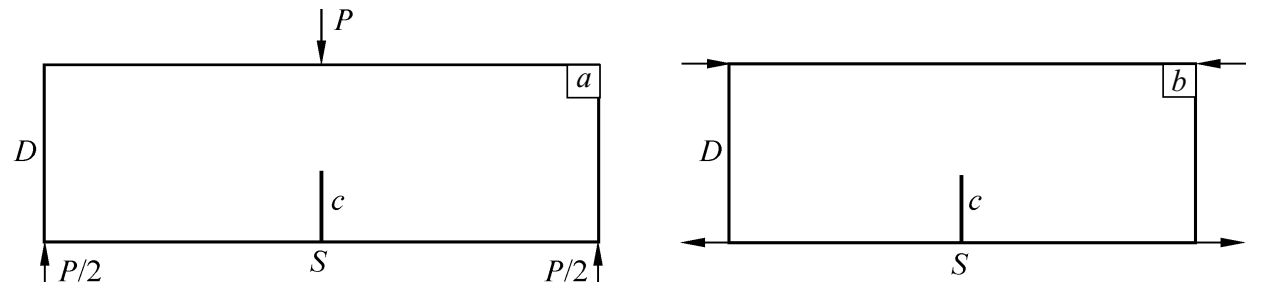

Fig. 3. A single edge notched beam subjected to three point bending $(a)$ or pure bending $(b)$. Each arrow represents a force of magnitude $M / D$

to interpreting the size effect of quasi-brittle materials [10, $21,22]$. We will therefore present briefly a computational procedure for obtaining the relevant coefficients.

\section{Stress intensity factor, $T$-term and coefficients of higher order terms in the Williams expansion for two typical specimen geometries}

Karihaloo and Xiao [16] extended a hybrid crack element, originally introduced by Tong et al. [23] for evaluating the stress intensity factor, so that it can be used for directly determining the stress intensity factor, as well as the coefficients of higher order terms in the plane elastic crack tip asymptotic field (27)-(31). This element has been used in conjunction with the four-node plane hybrid stress element PS [24] for the analysis of typical fracture specimens. In the analysis, the traction-free conditions on the boundary are exactly satisfied using the special hybrid stress boundary element HBE [25]. The main results are given below.

\subsection{Three-point bend single edge notched beam}

Karihaloo and Xiao [26, 27] analyzed three-point bend single-edge notched beams with span $S$, depth $D$ and crack length $c$ shown in Fig. 3. The crack to depth ratios from 0.05 to 0.8 are considered. $P$ and $M$ are the applied load and bending moment per unit thickness. Let $\alpha=c / D$ and $\beta=S / D$ be the crack to depth ratio and span to depth ratio, respectively.

The stress intensity factor, $T$-term $\left(T=4 a_{2}\right.$, the superscript 1 has been omitted) as well as coefficients $a_{n}(n>2)$ may be normalised to be dimensionless as

$$
\begin{aligned}
& k_{\beta}(\alpha)=\frac{a_{1}}{\sigma \sqrt{D}}, t_{\beta}(\alpha)=\frac{T}{\sigma}, g_{\beta}^{3}(\alpha)=\frac{a_{3}}{\sigma / \sqrt{D}}, \\
& g_{\beta}^{4}(\alpha)=\frac{a_{4}}{\sigma / D}, g_{\beta}^{5}(\alpha)=\frac{a_{5}}{\sigma / D^{1.5}},
\end{aligned}
$$

where $k_{\beta}(\alpha), t_{\beta}(\alpha), g_{\beta}^{3}(\alpha), g_{\beta}^{4}(\alpha)$ and $g_{\beta}^{5}(\alpha)$ are relevant dimensionless shape functions for each value of the span to depth ratio $\beta$. The stress $\sigma$ may be chosen arbitrarily though it is widely defined as $\sigma=6 M / D^{2}$, where $M$ is the bending moment per unit thickness in the central cross section. In case of pure bending, it is the external applied moment, and in the case of three-point bending $M=P S / 4$.
The stress intensity factor obtained in [26, 27] agrees well with the following general approximate closed-form expression, which is valid for any crack length and for any span to depth ratio larger than 2.5

$$
\begin{aligned}
k_{\beta}(\alpha) & =\frac{\sqrt{\alpha}}{\sqrt{2 \pi}(1-\alpha)^{3 / 2}(1+3 \alpha)} \times \\
& \times\left\{p_{\infty}(\alpha)+\frac{4}{\beta}\left[p_{4}(\alpha)-p_{\infty}(\alpha)\right]\right\},
\end{aligned}
$$

which is a combination of the shape functions for $\beta=4$ and for pure bending $(\beta=\infty)$, and

$$
\begin{aligned}
& p_{4}(\alpha)=1.9+0.41 \alpha+0.51 \alpha^{2}-0.17 \alpha^{3}, \\
& p_{\infty}(\alpha)=1.99+0.83 \alpha-0.31 \alpha^{2}+0.14 \alpha^{3} .
\end{aligned}
$$

Relationships similar to (39) for the stress intensity factor have been established for higher order terms in [26]. For a three-point bend single-edge notched beam with $\beta=4$, the dimensionless shape functions $t_{4}(\alpha), g_{4}^{3}(\alpha), g_{4}^{4}(\alpha)$ and $g_{4}^{5}(\alpha)$ can be fitted from the computed data as

$$
\begin{aligned}
& t_{4}(\alpha)=255.57 \alpha^{6}-509.68 \alpha^{5}+396.95 \alpha^{4}- \\
& \quad-145.71 \alpha^{3}+25.083 \alpha^{2}-0.633 \alpha-0.4302, \\
& g_{4}^{3}(\alpha)=-905.13 \alpha^{6}+1764.1 \alpha^{5}-1316.1 \alpha^{4}+ \\
& \quad+448.9 \alpha^{3}-65.833 \alpha^{2}+0.6362 \alpha+0.3744 \\
& g_{4}^{4}(\alpha)=78.959 \alpha^{6}+53.392 \alpha^{5}-296.38 \alpha^{4}+ \\
& \quad+273.68 \alpha^{3}-107.4 \alpha^{2}+19.628 \alpha-1.3681, \\
& g_{4}^{5}(\alpha)=-6028.7 \alpha^{7}+15928.4 \alpha^{6}-17417.3 \alpha^{5}+ \\
& \quad+10132.0 \alpha^{4}-3371.5 \alpha^{3}+638.82 \alpha^{2}-63.909 \alpha+2.4014 .
\end{aligned}
$$

For a single-edge notched beam subjected to pure bending $(\beta=\infty)$, the dimensionless shape functions $t_{\infty}(\alpha), g_{\infty}^{3}(\alpha)$, $g_{\infty}^{4}(\alpha)$ and $g_{\infty}^{5}(\alpha)$ have been fitted from the computed data and the expressions reported in [26].

A detailed validation of the results predicted by these general expressions with those computed by the hybrid crack element show that for three-point bend single-edge notched beams with span to depth ratios commonly used in testing, the general expressions predict highly accurate second and third terms, and tolerably accurate fourth and fifth terms; for details, see [26].

\subsection{Compact tension specimen}

Xiao and Karihaloo [28] computed the coefficients of the crack tip asymptotic field of a standard compact ten- 


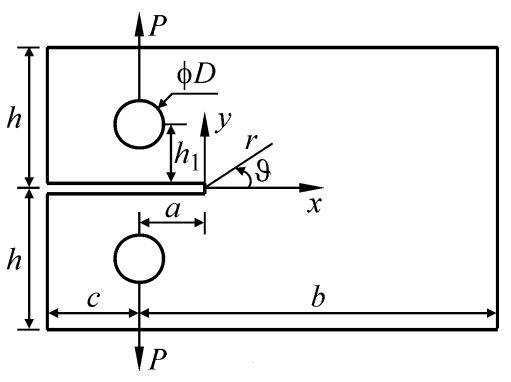

Fig. 4. A standard compact tension (CT) specimen. $h=0.6 b, h_{1}=$ $=0.275 b, D=0.25 b, c=0.25 b$, and thickness $B=b / 2 . P$ is the load per unit thickness

sion specimen shown in Fig. 4 for the crack length to depth ratio $\alpha$ from 0.05 to 0.8 . Here $\alpha=a / b$ and $\sigma=P / b$, where $P$ is the load per unit thickness (the symbols are defined in Fig. 4).

The stress intensity factor and the coefficients $a_{3}, a_{4}$ and $a_{5}$ of the third to fifth order terms may be normalized as (38) above by replacing $D$ with $b$. The T-term is normalised by $t(\alpha)=T /(4 \sigma)$. The computed dimensionless shape functions corresponding to coefficients $a_{n}(1 \leq n \leq 5)$ have been fitted with the following closed-form expressions to a very high accuracy

$$
\begin{aligned}
& k(\alpha)=373.08 \alpha^{5}-567.33 \alpha^{4}+321.47 \alpha^{3}- \\
& \quad-73.124 \alpha^{2}+9.8345 \alpha+0.8436 \\
& t(\alpha)=294.23 \alpha^{5}-520.3 \alpha^{4}+320.88 \alpha^{3}- \\
& \quad-71.418 \alpha^{2}+2.3668 \alpha+0.9443 \\
& g_{3}(\alpha)=-4774.1 \alpha^{6}+9231.3 \alpha^{5}-7083 \alpha^{4}+ \\
& \quad+2799.1 \alpha^{3}-664.26 \alpha^{2}+94.265 \alpha-7.6254 \\
& g_{4}(\alpha)=4013.8 \alpha^{6}-10191 \alpha^{5}+10688 \alpha^{4}- \\
& \quad-5797.4 \alpha^{3}+1639.3 \alpha^{2}-204.27 \alpha+5.4205 \\
& g_{5}(\alpha)=-24819 \alpha^{6}+60484 \alpha^{5}-58435 \alpha^{4}+ \\
& \quad+27760 \alpha^{3}-6422.2 \alpha^{2}+563.07 \alpha+3.4375
\end{aligned}
$$

The stress intensity factor widely reported in the literature in the range $0.35 \leq \alpha \leq 0.75$ agrees very well with $k(\alpha)$. Out of this range, the above formula should be used.

Note that the second $T$-term of the compact tension specimen $k(\alpha)$ is always positive, while for the notched three-point bend beam it varies from negative to positive when the crack is shallow to when it is deep. This has implications for crack growth stability.

\section{Fracture mechanics of heterogeneous materials}

The fracture behaviour of heterogeneous materials such as concrete, rock and coarse-grained ceramics, deviates significantly from the predictions of the linear elastic fracture mechanics. This is because such materials have a large process zone ahead of a traction-free crack in which the material exhibits softening. A fracture theory capable of describing the failure of such materials must necessarily be a nonlinear one, but we must distinguish the nonlinear fracture theory applicable to ductile materials, such as metals from that applicable to quasi-brittle materials, such as concrete, rock and ceramics. This is because in ductile materials the fracture process zone though small is surrounded by a large nonlinear plastic zone, whereas in quasi-brittle material the fracture process zone practically occupies the entire zone of nonlinear deformation. In contrast the nonlinear zone is practically absent in brittle materials. The above remarks are schematically illustrated in Fig. 5.

The first nonlinear theory of fracture mechanics for concrete-like materials was proposed by Hillerborg et al. [29]. It includes the tension softening fracture process zone through a fictitious crack ahead of the pre-existing crack whose faces are acted upon by certain closing stresses such that there is no stress concentration at the tip of this extended crack (Fig. 6). The term "fictitious" is used to underline the fact that this portion of the crack cannot be continuous with full separation of its faces, as in a real traction-free crack. It is clear that the fictitious crack model has some similarities with the Barenblatt and Dugdale-BCS models, discussed above. Like the Barenblatt and DugdaleBCS models, the fictitious crack model assumes that the fracture process zone is of negligible thickness (hence the alternative name discrete crack model) and the crack tip faces close smoothly. In fact, this smooth closure condition requires that $K_{\mathrm{I}}$ vanish at the tip and thus determines the size of the fracture process zone. The fictitious crack model however differs from both the Barenblatt and DugdaleBCS models in several important respects.

Firstly, unlike the Dugdale-BCS model, the closing stresses in the fracture process zone are not constant. They

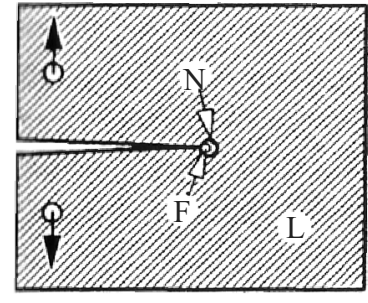

a

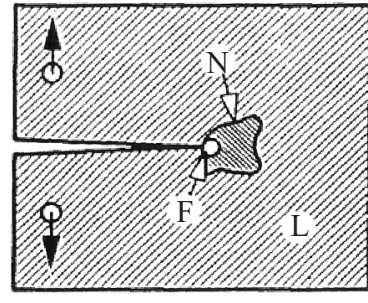

b

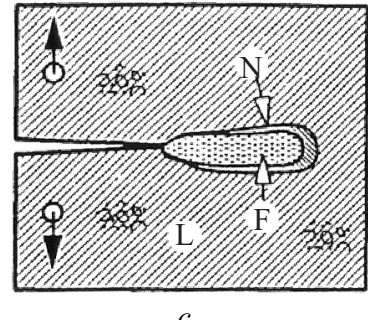

Fig. 5. Distinguishing features of fracture in a linear material $(a)$, a ductile material $(b)$, a quasi-brittle material $(c)$. L refers to linear elastic region, $\mathrm{N}$ to nonlinear zone, and $\mathrm{F}$ to fracture process zone [10] 

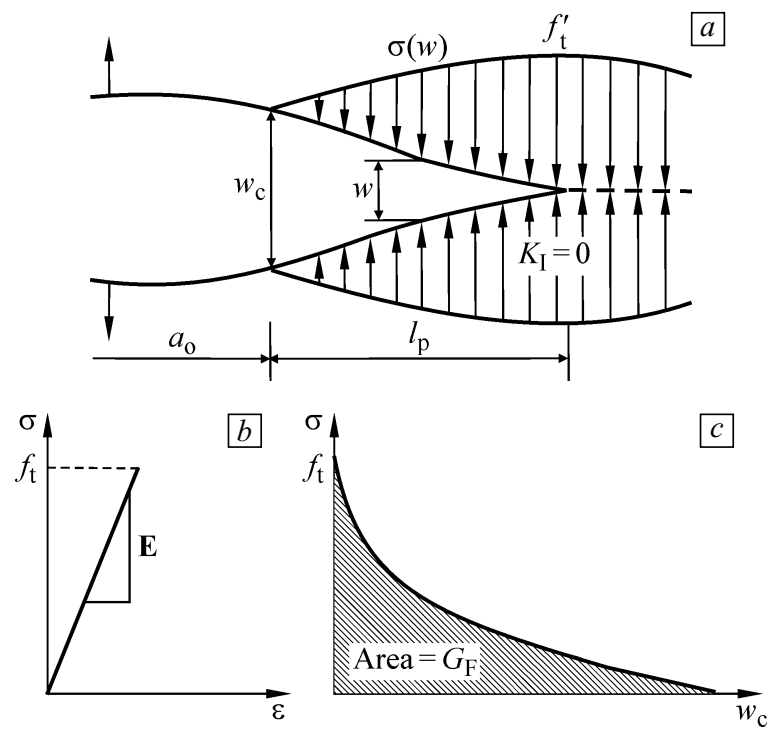

Fig. 6. A real traction-free crack of length $a_{0}$ terminating in a fictitious crack of length $l_{\mathrm{p}}$ whose faces close smoothly near its tip, $K_{\mathrm{I}}=0(a)$. The material ahead of the fictitious crack tip is assumed to be linear $(b)$, but the material within the fracture process zone is softening; the area under softening curve equals fracture energy $G_{\mathrm{F}}(c)[10]$

increase from a zero value at the tip of the pre-existing traction-free macrocrack (Fig. 6) to the full uniaxial tensile strength value of the material $f_{\mathrm{t}}^{\prime}$, at the tip of the fictitious crack. Moreover, the distribution of the closing stresses $\sigma(w)$ along the fracture process zone depends on the opening of the fictitious crack faces $w$.

Secondly, unlike the Barenblatt model, the size of the fracture process zone (cohesive zone in Barenblatt's model) may not be small in comparison with the length of the preexisting macrocrack. It follows, therefore, that knowledge of the distribution of closing stresses $\sigma(w)$ along the fracture process zone is now essential if we are to make any use of the smooth crack closure condition. That being so, it also follows that the fracture of concrete cannot be described by a single material parameter, such as $K_{\text {Ic }}$ or $G_{\text {Ic }}$, as in the case of brittle materials. For this description, it is now necessary to have at least two material parameters.

In the fictitious crack model these two material parameters are (i) the stress-displacement relation $\sigma(w)$ in the softening zone, and (ii) the area under the tension softening curve which is now the true specific fracture energy $G_{\mathrm{F}}$ (Fig. 6c)

$$
G_{\mathrm{F}}=\int_{f_{\mathrm{t}}^{\prime}}^{0} w(\sigma) \mathrm{d} \sigma=\int_{0}^{w_{\mathrm{c}}} \sigma(w) \mathrm{d} w
$$

where $f_{\mathrm{t}}^{\prime}$ is the tensile strength of the material and $w_{\mathrm{c}}$ the critical opening displacement at the pre-existing macrocrack tip when it begins to grow.
Instead of $\sigma(w)$ and $G_{\mathrm{F}}$, any combination of two independent parameters may be chosen. For example, it could be $w_{\mathrm{c}}$ and $G_{\mathrm{F}}$, or even $\sigma(w)$ and a derived parameter $l_{\mathrm{ch}}=$ $=E^{\prime} G_{\mathrm{F}} / f_{\mathrm{t}}^{\prime 2}$, called the characteristic length of the material [29]. The determination of all two-parameter combinations of material properties is fraught with difficulties. Experimental procedures have recently been proposed in [30, 31]. A cohesive crack in quasi-brittle materials will propagate once the principal tensile stress at the tip of the fictitious crack reaches $f_{\mathrm{t}}^{\prime}$, and the traction-free crack will propagate when its tip opening displacement reaches the critical value $w_{\mathrm{c}}$. Once the fictitious crack has begun to propagate, its direction will depend on the asymptotic stress field ahead of the fictitious crack tip which will depend on the geometry and loading on the structure and on the shape of the softening curve $\sigma(w)$. We shall next describe how the asymptotic stress and displacement fields can be solved.

\section{Asymptotic fields at frictionless and frictional cohesive crack tips in quasi-brittle materials}

The lack of any work on the asymptotic fields at the tips of cohesive cracks belies the widespread use of cohesive crack models. The solution of asymptotic fields at cohesive crack tips in quasi-brittle materials was obtained very recently in [7]. They considered only normal cohesive separation, but allowed for the effect of Coulomb friction on the cohesive crack faces. The special case of a pure mode I cohesive crack was fully investigated. Their solution is valid for any separation law that can be expressed in a special polynomial form. They showed that many commonly used separation laws of quasi-brittle materials, e.g. rectangular, linear, bilinear, exponential, etc can be easily expressed in this form. They used these asymptotic fields as enrichment functions in the extended/generalized finite element method at the tip of long cohesive cracks, as well as short branches/ kinks.

In order to simplify the derivation of the cohesive crack tip asymptotic fields, we will represent cohesion-separation law by the following general polynomial

$$
\frac{\sigma}{f_{\mathrm{t}}}=1+\sum_{i=1}^{5} \alpha_{i}\left(\frac{w}{w_{\mathrm{c}}}\right)^{2 / 3 i}-\left(1+\sum_{i=1}^{5} \alpha_{i}\right)\left(\frac{w}{w_{\mathrm{c}}}\right)^{4},
$$

where $\alpha_{i}(i=1-5)$ are fitting parameters. Xiao and Karihaloo [7] showed that the commonly used exponential (45), linear (46), bilinear (47) and rectangular (48) cohesionseparation laws given below can be faithfully expressed in the general form (44):

$$
\begin{aligned}
& \frac{\sigma}{f_{\mathrm{t}}}=f\left(\frac{w}{w_{\mathrm{c}}}\right)-\frac{w}{w_{\mathrm{c}}} f(1), \\
& f\left(\frac{w}{w_{\mathrm{c}}}\right)=\left[1+\left(C_{1} \frac{w}{w_{\mathrm{c}}}\right)^{3}\right] e^{-C_{2} w / w_{\mathrm{c}}}, \\
& \hat{\sigma}=1-\hat{w},
\end{aligned}
$$




$$
\begin{gathered}
\hat{\sigma}=\left\{\begin{array}{l}
1-\left(1-\hat{f}_{1}\right) \frac{\hat{w}}{\hat{w}_{1}}, 0 \leq \hat{\sigma} \leq \hat{f}_{1}, \\
\frac{\hat{f}_{1}}{1-\hat{w}_{1}}(1-\hat{w}), \quad \hat{f}_{1}<\hat{\sigma} \leq 1,
\end{array}\right. \\
\hat{\sigma}^{m}+\hat{w}^{2 m}=1 \text { or } \hat{\sigma}=1-\hat{w}^{2 n} .
\end{gathered}
$$

In (45)-(48), $C_{1}, C_{2}, m, n$ are material constants, $\hat{\sigma}=$ $=\sigma / f_{\mathrm{t}}, \hat{w}=w / w_{\mathrm{c}}, \quad \hat{f}_{1}=f_{1} / f_{\mathrm{t}}$, and $\hat{w}_{1}=w_{1} / w_{\mathrm{c}}$, where $w_{1}$ and $f_{1}$ are the co-ordinates of the knee of the bilinear law. Xiao and Karihaloo [7] used the eigenfunction expansion method of Williams [6] and combined it with the complex function formalism of Muskhelishvili [15] in the spirit of Sih and Liebowitz [14] to solve the fields, in exactly the same manner as (19)-(22) above. The cohesive and frictional laws on the crack faces were imposed through appropriate boundary conditions. For a general plane mixed mode I + II problem, the complex functions $\phi(z)$ and $\chi(z)$ were chosen as series of complex eigenvalue Goursat functions (23) denoting $a_{1 n}=a_{n}^{1}, a_{2 n}=a_{n}^{2}, b_{1 n}=b_{n}^{1}$ and $b_{2 n}=$ $=b_{n}^{2}$.

To complete the asymptotic analysis of the crack tip fields, solutions need to satisfy the proper symmetry conditions along the line of extension of the cohesive crack, and boundary conditions on the cohesive crack faces.

If the crack faces are traction-free (i.e. there is no cohesive zone), we have (24).

If normal cohesive separation applies to the crack faces, relationship (44) needs to be satisfied over the cohesive zone. The stresses at the cohesive crack tip are nonsingular (because the stress intensity factor $K_{\mathrm{I}}=0$ ). Moreover, the following conditions need to be satisfied:

(a) if the cohesive crack faces are frictionless

$$
\left.\sigma_{y}\right|_{\theta=\pi}=\left.\sigma_{y}\right|_{\theta=-\pi} \neq 0,\left.\tau_{x y}\right|_{\theta=\pi}=\left.\tau_{x y}\right|_{\theta=-\pi}=0,
$$

(b) if the Coulomb friction is considered

$$
\begin{aligned}
& \left.\sigma_{y}\right|_{\theta=\pi}=\left.\sigma_{y}\right|_{\theta=-\pi} \neq 0, \\
& \left.\tau_{x y}\right|_{\theta=\pi}=\left.\tau_{x y}\right|_{\theta=-\pi}=-\left.\mu_{\mathrm{f}} \sigma_{y}\right|_{\theta= \pm \pi} \neq 0,
\end{aligned}
$$

where $\mu_{\mathrm{f}}$ equals the positive or negative value of the coefficient of kinetic friction, which is assumed to be constant, depending on the relative sliding direction of the two crack faces. Specifically, $\mu_{\mathrm{f}}>0$ when $\delta>0$ and $\mu_{\mathrm{f}}<0$ when $\delta<0$. tion

(c) if the cohesive crack faces are in pure mode I condi-

$$
\begin{aligned}
& \left.\sigma_{y}\right|_{\theta=\pi}=\left.\sigma_{y}\right|_{\theta=-\pi} \neq 0,\left.\tau_{x y}\right|_{\theta=\pi}=\left.\tau_{x y}\right|_{\theta=-\pi}=0, \\
& \left.\tau_{x y}\right|_{\theta=0}=0, \text { and }\left.v\right|_{\theta=0}=0 .
\end{aligned}
$$

In all three situations, the length of the process (cohesive) zone is either prescribed (i.e. an initial cohesive zone exists before the loading is applied, and does not propagate under the present loading) or is determined by the condition $w=w_{\mathrm{c}}$ in the normal cohesion-separation rela- tion (44) at the instant of growth of the pre-existing traction-free crack.

\section{Frictionless cohesive crack with normal cohesive separation}

The relationship (44) between cohesion and normal separation will be discussed below. After considering conditions (49) on the crack faces, the solutions are composed of two parts. The first part corresponds to integer eigenvalues

$$
\text { (a) } \lambda_{n}=n+1, b_{2 n}=-\frac{n}{n+2} a_{2 n}, n=0,1,2, \ldots,
$$
giving

$$
\hat{\sigma}_{y}=\frac{\left.\sigma_{y}\right|_{\theta= \pm \pi}}{f_{\mathrm{t}}}=\sum_{n=0} c_{n} r^{n}=1+\sum_{n=1} c_{n} r^{n},
$$

where

$$
\begin{aligned}
& c_{n}=\frac{(n+2)(n+1)\left(a_{1 n}+b_{1 n}\right) \cos (n \pi)}{f_{\mathrm{t}}}, \\
& c_{0}=\frac{2\left(a_{10}+b_{10}\right)}{f_{\mathrm{t}}}=1
\end{aligned}
$$

since $\left.\sigma_{y}\right|_{\theta= \pm \pi}=f_{\mathrm{t}}$ when $r \rightarrow 0$.

The opening and sliding displacements of the cohesive crack faces vanish for integer eigenvalues

$$
w=0 \text { and } \delta=0 \text {. }
$$

The second part of the asymptotic solutions corresponds to non-integer eigenvalues

$$
\begin{aligned}
& \text { (b) } \lambda_{n}=\frac{2 n+3}{2}, \\
& b_{1 n}=-\frac{2 n+1}{2 n+5} a_{1 n}, b_{2 n}=-a_{2 n}, n=0,1,2, \ldots,
\end{aligned}
$$

giving

$$
\begin{aligned}
& \left.\sigma_{y}\right|_{\theta= \pm \pi}=0, \\
& \hat{w}=\frac{w}{w_{\mathrm{c}}}=\sum_{n=0} \bar{d}_{n} r^{(2 n+3) / 2}, \\
& \bar{d}_{n}=\frac{\left[\left(\kappa+\frac{2 n+3}{2}\right) a_{1 n}+\frac{2 n+5}{2} b_{1 n}\right] \sin \left(\frac{2 n+3}{2} \pi\right)}{\mu w_{\mathrm{c}}}, \\
& \delta=\sum_{n=0} \frac{r^{2 n+3 / 2}}{\mu}\left[\left(\frac{2 n+3}{2}-\kappa\right) a_{2 n}+\frac{2 n+5}{2} b_{2 n}\right] \times \\
& \quad \times \sin \left(\frac{2 n+3}{2} \pi\right) .
\end{aligned}
$$

Consider the truncated $N+1$ terms of $\hat{w}$ (58), and denote $d_{0}=\bar{d}_{0}, d_{n}=\bar{d}_{n} / d_{0}(n>1)$

$$
\hat{w}=d_{0} r^{3 / 2}\left(1+\sum_{n=1}^{N} d_{n} r^{n}\right) \text {. }
$$

The expansion of $\hat{w}$ raised to the power $2 i / 3$ is also truncated to $N+1$ terms, since these terms include only the truncated $N+1$ terms of $\hat{w}$. Hence

$$
\hat{w}^{2 / 3 i}=d_{0}^{2 / 3 i} r^{i}\left(1+\sum_{n=1}^{N} \beta_{i n} r^{n}\right)
$$


where

$$
\beta_{i n}=\frac{f_{i}^{(n)}(0)}{n !}, f_{i}(r)=\left(1+\sum_{n=1}^{N} d_{n} r^{n}\right)^{2 / 3 i},
$$

where $f_{i}^{(n)}(0)$ denotes the $n$th derivative at $r=0$.

The derivatives of function $f_{i}(r)(62)$ are given in [7] and the corresponding first five coefficients $\beta_{i n}$ are

$$
\begin{aligned}
& \beta_{i 1}=\frac{2}{3} i d_{1}, \\
& \beta_{i 2}=\frac{1}{3} i\left(\frac{2}{3} i-1\right) d_{1}^{2}+\frac{2}{3} i d_{2}, \\
& \beta_{i 3}=\frac{1}{9} i\left(\frac{2}{3} i-1\right)\left(\frac{2}{3} i-2\right) d_{1}^{3}+ \\
& +\frac{2}{3} i\left(\frac{2}{3} i-1\right) d_{1} d_{2}+\frac{2}{3} i d_{3}, \\
& \beta_{i 4}=\frac{1}{36} i\left(\frac{2}{3} i-1\right)\left(\frac{2}{3} i-2\right)\left(\frac{2}{3} i-3\right) d_{1}^{4}+ \\
& +\frac{1}{3} i\left(\frac{2}{3} i-1\right)\left(\frac{2}{3} i-2\right) d_{1}^{2} d_{2}+ \\
& +\frac{1}{3} i\left(\frac{2}{3} i-1\right) d_{2}^{2}+\frac{2}{3} i\left(\frac{2}{3} i-1\right) d_{1} d_{3}+\frac{2}{3} i d_{4}, \\
& \beta_{i 5}=\frac{1}{180} i\left(\frac{2}{3} i-1\right)\left(\frac{2}{3} i-2\right)\left(\frac{2}{3} i-3\right)\left(\frac{2}{3} i-4\right) d_{1}^{5}+ \\
& +\frac{1}{9} i\left(\frac{2}{3} i-1\right)\left(\frac{2}{3} i-2\right)\left(\frac{2}{3} i-3\right) d_{1}^{3} d_{2}+ \\
& +\frac{1}{3} i\left(\frac{2}{3} i-1\right)\left(\frac{2}{3} i-2\right) d_{1} d_{2}^{2}+ \\
& +\frac{1}{3} i\left(\frac{2}{3} i-1\right)\left(\frac{2}{3} i-2\right) d_{1}^{2} d_{3}+ \\
& +\frac{2}{3} i\left(\frac{2}{3} i-1\right) d_{2} d_{3}+\frac{2}{3} i\left(\frac{2}{3} i-1\right) d_{1} d_{4}+\frac{2}{3} i d_{5} .
\end{aligned}
$$

With the use of (61), if we choose $N=5$, then after satisfying the cohesive relationship (44) we can obtain the following expressions for coefficients $c_{n}$ appearing in (53) (see [7]):

$$
\begin{aligned}
c_{1}= & \alpha_{1} d_{0}^{2 / 3}, \\
c_{2} & =\alpha_{2} d_{0}^{4 / 3}+\alpha_{1} d_{0}^{2 / 3} \beta_{11}, \\
c_{3} & =\alpha_{3} d_{0}^{2}+\alpha_{1} d_{0}^{2 / 3} \beta_{12}+\alpha_{2} d_{0}^{4 / 3} \beta_{21}, \\
c_{4} & =\alpha_{4} d_{0}^{8 / 3}+\alpha_{1} d_{0}^{2 / 3} \beta_{13}+\alpha_{2} d_{0}^{4 / 3} \beta_{22}+\alpha_{3} d_{0}^{2} \beta_{31}, \\
c_{5}= & \alpha_{5} d_{0}^{10 / 3}+\alpha_{1} d_{0}^{2 / 3} \beta_{14}+\alpha_{2} d_{0}^{4 / 3} \beta_{23}+ \\
& +\alpha_{3} d_{0}^{2} \beta_{32}+\alpha_{4} d_{0}^{8 / 3} \beta_{41}, \\
c_{6} & =\alpha_{1} d_{0}^{2 / 3} \beta_{15}+\alpha_{2} d_{0}^{4 / 3} \beta_{24}+\alpha_{3} d_{0}^{2} \beta_{33}+\alpha_{4} d_{0}^{8 / 3} \beta_{42}+ \\
& +\alpha_{5} d_{0}^{10 / 3} \beta_{51}-\left(1+\sum_{i=1}^{5} \alpha_{i}\right) d_{0}^{4}, \\
c_{7}= & \alpha_{2} d_{0}^{4 / 3} \beta_{25}+\alpha_{3} d_{0}^{2} \beta_{34}+\alpha_{4} d_{0}^{8 / 3} \beta_{43}+\alpha_{5} d_{0}^{10 / 3} \beta_{52}- \\
& -\left(1+\sum_{i=1}^{5} \alpha_{i}\right) d_{0}^{4} \beta_{61},
\end{aligned}
$$

$$
\begin{aligned}
c_{8} & =\alpha_{3} d_{0}^{2} \beta_{35}+\alpha_{4} d_{0}^{8 / 3} \beta_{44}+\alpha_{5} d_{0}^{10 / 3} \beta_{53}- \\
& -\left(1+\sum_{i=1}^{5} \alpha_{i}\right) d_{0}^{4} \beta_{62}, \\
c_{9}= & \alpha_{4} d_{0}^{8 / 3} \beta_{45}+\alpha_{5} d_{0}^{10 / 3} \beta_{54}-\left(1+\sum_{i=1}^{5} \alpha_{i}\right) d_{0}^{4} \beta_{63}, \\
c_{10} & =\alpha_{5} d_{0}^{10 / 3} \beta_{55}-\left(1+\sum_{i=1}^{5} \alpha_{i}\right) d_{0}^{4} \beta_{64}, \\
c_{11} & =-\left(1+\sum_{i=1}^{5} \alpha_{i}\right) d_{0}^{4} \beta_{65} .
\end{aligned}
$$

Note that the above asymptotic solution is not for pure mode I cohesive crack tip (cf. (49) and (51)), since along the line of extension of the crack, $\theta=0$, the shear stress does not vanish $\left(\tau_{x y} \neq 0\right)$.

For non-integer eigenvalues (56), the coefficients $a_{1 n}$ and $a_{2 n}$ may be regarded as independent, so that coefficients $b_{1 n}$ are linearly dependent on $a_{1 n}$ and $b_{2 n}$ on $a_{2 n}$. For integer eigenvalues (52), coefficients $a_{1 n}$ and $a_{2 n}$ may also be regarded as independent, so that coefficients $b_{2 n}$ now depend linearly on $a_{2 n}$. However, the coefficients $b_{1 n}$ for integer eigenvalues will depend both linearly on $a_{1 n}$ for integer eigenvalues and nonlinearly on $a_{1 n}$ for noninteger eigenvalues via (54), (58), (60), and (62)-(64). The inherent nonlinear nature of the problem is reflected in these nonlinear relationships between the coefficients of the asymptotic fields.

The displacements corresponding to $\lambda_{-1}=0$, or $n=-1$ in (52) are rigid body translations at the crack tip

$$
2 \mu u_{-1}=\kappa a_{1,-1}-b_{1,-1}, 2 \mu v_{-1}=\kappa a_{2,-1}+b_{2,-1} .
$$

The displacements corresponding to $a_{20}\left(n=0, \lambda_{0}=1\right.$ and $b_{20}=0$ from (52)) represents rigid body rotation with respect to the crack tip

$$
2 \mu \hat{u}_{0}=-r(\kappa+1) a_{20} \sin \theta, 2 \mu \hat{v}_{0}=r(\kappa+1) a_{20} \cos \theta .(66)
$$

\section{Coulomb frictional cohesive crack with normal cohesive separation}

In principle, a cohesive relationship can also be considered in the tangential direction for quasi-brittle materials. However, this is a contentious issue, since it is difficult to separate the cohesive-sliding relation from the frictional force between the rough cohesive crack faces. Hence we will only consider the Coulomb friction between the crack faces instead of a tangential cohesive relationship. The corresponding boundary conditions are (50).

The complete asymptotic solutions are again composed of two parts. The first part corresponding to integer eigenvalues is similar to case (a) in Sect. 9 but with different constraints on the coefficients

$$
\begin{aligned}
& \lambda_{n}=n+1, \\
& n a_{2 n}+(n+2) b_{2 n}=-\mu_{\mathrm{f}}(n+2)\left(a_{1 n}+b_{1 n}\right), \\
& n=0,1,2, \ldots .
\end{aligned}
$$


From (67), we have

$$
b_{2 n}=-\frac{n}{n+2} a_{2 n}-\mu_{\mathrm{f}}\left(a_{1 n}+b_{1 n}\right) .
$$

When $\mu_{\mathrm{f}}=0$, the cohesive crack faces are frictionless, and (67) reduces to (52). These solutions have nonzero $\sigma_{y}$ and $\tau_{x y}$ along the cohesive crack faces, but zero crack opening $w$ and sliding $\delta$. The second part of the asymptotic solutions corresponding to non-integer eigenvalues satisfy

$$
\begin{aligned}
& b_{1 n}=-\frac{\lambda_{n}-1}{\lambda_{n}+1} a_{1 n}, b_{2 n}=-a_{2 n}, \\
& \left(\mu_{\mathrm{f}} a_{1 n}-a_{2 n}\right) \cos \left[\left(\lambda_{n}-1\right) \pi\right]=0 .
\end{aligned}
$$

Assuming that

$$
\mu_{\mathrm{f}} a_{1 n}-a_{2 n} \neq 0 \text {, }
$$

the third equation in (69) gives

$$
\cos \left[\left(\lambda_{n}-1\right) \pi\right]=0,
$$

so that the second part of asymptotic solutions is identical to (b) of Sect. 9 (i.e., (57)-(59)).

The remaining solution procedure and final asymptotic solutions as well as the dependence of the coefficients are similar to those in Sect. 9. Equations (65) and (66) again represent the rigid body modes for the present case.

Finally, we give without details the leading term in the asymptotic displacement field of a pure mode I cohesive crack (with the boundary conditions (51)). This term is given by the lowest non-integer eigenvalue

$$
\begin{aligned}
& u=\frac{r^{3 / 2}}{2 \mu} a_{11}\left[\left(\kappa+\frac{1}{2}\right) \cos \left(\frac{3}{2} \theta\right)-\frac{3}{2} \cos \left(\frac{1}{2} \theta\right)\right], \\
& v=\frac{r^{3 / 2}}{2 \mu} a_{11}\left[\left(\kappa-\frac{1}{2}\right) \sin \left(\frac{3}{2} \theta\right)-\frac{3}{2} \sin \left(\frac{1}{2} \theta\right)\right],
\end{aligned}
$$

where the coefficient $a_{11}$ depends on the geometry and loading of the structure and on the cohesion-separation law.

The choice of the special form of the cohesion-separation relation (44) involving as it does fractional powers of the nondimensional separation, $\hat{w}=w / w_{\mathrm{c}}$ may seem strange but it ensures that the asymptotic fields at the cohesive crack tip are separable into radial and angular variations exactly as the Williams expansions at a traction-free crack tip. In a subsequent paper [8], it was shown that separable asymptotic crack tip fields are also obtainable for the cohesion-separation relation involving integer powers of the nondimensional separation, $\hat{w}=w / w_{\mathrm{c}}$.

\section{Implementation of the asymptotic fields in XFEM/GFEM}

In the implementation of the cohesive crack asymptotic fields as enrichment functions in the XFEM/GFEM, if not only the first term but also the higher order terms are used as in [32], the linear dependence of the coefficients can be enforced in advance, while the nonlinear dependence of the coefficients can be enforced as constraints in the solution process. It is more convenient to use only the leading term of the displacement asymptotic field at the tip of a cohesive crack (which ensures a displacement discontinuity normal to the cohesive crack face) as the enrichment function, as in most implementations of the XFEM in the literature. The complete implementation with several examples can be found in [33-35].

\section{Concluding remarks}

We provided an overview of Griffith's global energy criterion for onset of fast fracture in brittle materials, followed by that of Irwin's local stress criterion. We showed that these two criteria are equivalent for brittle materials and pointed out their limitations which were overcome by the introduction of an infinitesimally small fracture process (i.e. cohesive) zone at the crack tip. We then gave the asymptotic stress and displacement fields at the tip of a crack which are necessary for establishing the direction of propagation of a growing crack. We also showed how modern computational tools can be used to calculate accurately the coefficients of the singular and higher order terms of these fields. Next we introduced the fictitious crack model for the fracture of quasi-brittle materials whose fracture process zone can be very large. These materials, unlike the brittle materials, require two parameters for describing their fracture behaviour, for example the specific fracture energy and the shape of the tension softening diagram. We gave asymptotic stress and displacement fields at the tip of a cohesive crack whose tension softening diagram is linear, bilinear, exponential or rectangular. As with the brittle materials, these fields are required for determining the direction of growth of a propagating cohesive crack.

\section{References}

1. Wieghardt K. Ueber das Spalten und Zerreissen elastischer Koerper // Z. Math. Phys. - 1907. - V. 55. - P. 60-103; On splitting and cracking of elastic bodies (Ed. by H.P. Rossmanith) // Fatigue Fract. Eng. Mater. Struct. - 1995. - V. 12. - P. 1371-1405.

2. Griffith A.A. The phenomena of rupture and flow in solids // Philos. Trans. Roy. Soc. Lond. A. - 1920. - V. 221. - P. 163-198.

3. Irwin G.R. Analysis of stresses and strains near the end of a crack traversing a plate // ASME J. Appl. Mech. - 1957. - V. 24. - P. 361364.

4. Barenblatt G.I. On equilibrium cracks forming during brittle fracture // PMM. - 1959. - V. 23. - P. 434-444.

5. Barenblatt G.I. The mathematical theory of equilibrium cracks in brittle fracture // Adv. Appl. Mech. - 1962. - V. 7. - P. 55-129.

6. Williams M.L. On the stress distribution at the base of a stationary crack // ASME J. Appl. Mech. - 1957. - V. 24. - P. 109-114.

7. Xiao Q.Z., Karihaloo B.L. Asymptotic fields at frictionless and frictional cohesive crack tips in quasi-brittle materials // J. Mech. Mater. Struct. - 2006. - V. 1. - P. 881-910.

8. Karihaloo B.L., Xiao Q.Z. Asymptotic fields at the tip of a cohesive crack // Int. J. Fracture. - 2008. -V. 150. - P. 55-74.

9. Inglis C.E. Stresses in a plate due to the presence of cracks and sharp notches // Trans. Inst. Naval Architects. - 1913. - V. 55. - P. 219-241.

10. Karihaloo B.L. Fracture Mechanics and Structural Concrete. - Harlow, UK: Addison Wesley Longman, 1995.

11. Karihaloo B.L., Xiao Q.Z. Linear and Non-Linear Fracture Mechanics // Comprehensive Structural Integrity. Vol. 2 / Ed. by B.L. Karihaloo, W.G. Knauss. - Oxford: Elsevier, 2003. - P. 81-212. 
12. Dugdale D.S. Yielding of steel sheets containing slits // J. Mech. Phys. Solids. - 1960. - V. 8. - P. 100-104.

13. Bilby B.A., Cottrell A.H., Swindon K.H. The spread of plastic yield from a notch // Proc. Roy. Soc. Lond. A. - 1963. - V. 272. - P. 304314.

14. Sih G.C., Liebowitz H. Mathematical Theories of Brittle Fracture // Fracture: An Advanced Treatise. Vol. II / Ed. by H. Liebowitz. - New York: Academic Press, 1968. - P. 67-190.

15. Muskhelishvili N.I. Some Basic Problems of Mathematical Theory of Elasticity. - Groningen: Noordhoff, 1953. -257 p.

16. Karihaloo B.L., Xiao Q.Z. Accurate determination of the coefficients of elastic crack tip asymptotic field by a hybrid crack element with padaptivity // Eng. Fract. Mech. - 2001. - V. 68. - P. 1609-1630.

17. Tada H., Paris P.C., Irwin G.R. The Stress Analysis of Cracks Handbook. - St. Louis, USA: Paris Productions, 1985.

18. Murakami Y. Stress Intensity Factors Handbook. - New York: Pergamon, 1986.

19. O'Dowd N.P., Shih C.F. Family of crack-tip fields characterized by a triaxiality parameter: I. Structure of fields // J. Mech. Phys. Solids. 1991. - V. 39. - P. 989-1015.

20. Du Z-Z., Hancock J.W. The effect of non-singular stresses on cracktip constraint // J. Mech. Phys. Solids. - 1991. - V. 39. - P. 555-567.

21. Karihaloo B.L. Size effect in shallow and deep notched quasi-brittle materials // Int. J. Fracture. - 1999. - V. 95. - P. 379-390.

22. Karihaloo B.L., Abdalla H.M., Xiao Q.Z. Size effect in concrete beams // Eng. Fract. Mech. - 2003. - V. 70. - P. 979-993.

23. Tong P., Pian T.H.H., Lasry S.J. A hybrid element approach to crack problems in plane elasticity // Int. J. Numer. Meth. Eng. - 1973. V. 7. - P. 297-308.

24. Pian T.H.H., Sumihara K. Rational approach for assumed stress finite elements // Int. J. Numer. Meth. Eng. - 1984. - V. 20. - P. 16851695.

25. Xiao Q.Z., Karihaloo B.L., Williams F.W. Application of penaltyequilibrium hybrid stress element method to crack problems // Eng. Fract. Mech. -1999 . - V. 63. - P. 1-22.
26. Karihaloo B.L., Xiao Q.Z. Higher-order terms of the crack tip asymptotic field for a notched three-point bend beam // Int. J. Fracture. - 2001. - V. 112. - P. 111-128.

27. Xiao Q.Z., Karihaloo B.L. Direct evaluation of accurate coefficients of the linear elastic crack tip asymptotic field // Fatig. Fract. Eng. Mater. Struct. - 2003. - V. 25. - P. 719-729.

28. Xiao Q.Z., Karihaloo B.L. Coefficients of the crack tip asymptotic field for a standard compact tension specimen // Int. J. Fracture. 2002. - V. 118. - P. 1-15.

29. Hillerborg A., Modéer M., Petersson P.E. Analysis of crack formation and crack growth in concrete by means of fracture mechanics and finite elements // Cement Concr. Res. - 1976. - V. 6. - P. 773782.

30. Abdalla H.M., Karihaloo B.L. A method for constructing the bilinear tension softening diagram of concrete corresponding to its true fracture energy // Mag. Concr. Res. - 2004. - V. 56. - P. 597-604.

31. Karihaloo B.L., Abdalla H.M., Imjai T. A simple method for determining the true specific fracture energy of concrete // Mag. Concr. Res. -2003 . - V. 55. - P. 471-481.

32. Liu X.Y., Xiao Q.Z., Karihaloo B.L. XFEM for direct evaluation of mixed mode SIFs in homogeneous and bi-materials // Int. J. Numer. Meth. Eng. - 2004. - V. 59. - P. 1103-1118.

33. Xiao Q.Z., Karihaloo B.L., Liu X.Y. Incremental-secant modulus iteration scheme and stress recovery for simulating cracking process in quasi-brittle materials using XFEM // Int. J. Numer. Meth. Eng. 2007. - V. 69. - P. 2606-2635.

34. Karihaloo B.L., Xiao Q.Z. Asymptotic fields ahead of mixed mode frictional cohesive cracks // Z. Angew. Math. Mech. (ZAMM). 2010. - V. 90. - P. 710-720.

35. Karihaloo B.L., Xiao Q.Z. Accurate simulation of mixed mode cohesive crack propagation in quasi-brittle structures using exact asymptotic fields in XFEM: An overview // J. Mech. Mater. Struct. - 2011. V. 6. - P. 267-276.

Received October 01, 2018 revised October 01, 2018, accepted October 08,2018

Сведения об авторах

Bhushan L. Karihaloo, Emeritus Professor, PhD, DEng, DSc (hc), FLSW, ForMemRAE, Cardiff University, UK, karihaloob@cardiff.ac.uk Qi-Zhi Xiao, LUSAS FEA Ltd., Kingston-upon-Thames, UK, qizhi.xiao@lusas.com 